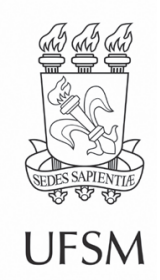

\title{
Artigos
}

\section{Fragmentação da paisagem no entorno e na Reserva de Desenvolvimento Sustentável Nascentes das Geraizeiras, Minas Gerais}

\author{
Landscape fragmentation in a buffer zone and the Nascentes das \\ Geraizeiras Sustainable Development Reserve, Minas Gerais
}

\author{
Marizete Chaves Cerqueira' \\ Eraldo Aparecido Trondoli Matricardi" $\odot$ \\ Aldicir Osni Scariot ${ }^{\prime \prime \prime} \odot$ \\ Carlos Henke de Oliveiralv $\odot$ \\ 'Pesquisadora Autônoma, Brasília, DF, Brasil \\ "Universidade de Brasília, Brasília, DF, Brasil \\ I'Empresa Brasileira de Pesquisa Agropecuária, Brasília, DF, Brasil \\ "vniversidade de Brasília, Brasília, DF, Brasil
}

\section{RESUMO}

A expansão de áreas de pastagens e cultivos agrícolas foi responsável pela maior parte do desmatamento no norte do estado de Minas Gerais. No presente estudo, avaliou-se a dinâmica do uso e cobertura da terra ocorrida nas últimas décadas (1986 a 2015) na Reserva de Desenvolvimento Sustentável Nascentes das Geraizeiras (RDS-NG) e em uma zona de 10 km do seu entorno no estado de Minas Gerais. Avaliaramse também os efeitos do desmatamento sobre a fragmentação da vegetação natural usando dados de sensoriamento remoto e análise da paisagem. Os resultados deste estudo indicam que o desmatamento afetou mais da metade da vegetação natural até 2015, agravando a integridade dos fragmentos de vegetação nativa na área de estudo. A RDS-NG contribuiu para mitigar a fragmentação da vegetação natural ocorrida no entorno daquela Reserva com a regeneração natural de algumas áreas degradadas. Observou-se que a maior ameaça ambiental à reserva é a ocorrência do fogo, que varia anualmente em extensão e danos socioambientais. O uso sustentado das terras na RDS-NG pode ser melhorado com a ampliação das práticas de atividades econômicas sustentáveis, como o aproveitamento de produtos florestais não madeireiros, a implantação de consórcios agroflorestais e outras atividades econômicas de forma moderada. Essas práticas contribuirão para garantir a manutenção dos recursos naturais, a produção econômica e a geração de renda e trabalho à comunidade local, com inclusão de todos os segmentos sociais da população da Reserva e seu entorno.

Palavras-chave: Unidade de Conservação; Análise da paisagem; Cerrado 


\section{ABSTRACT}

The expansion of pastures and cropping fields was responsible for most deforestation in Northern Minas Gerais state. In this study, we assessed the dynamics of land use and cover that occurred in recent decades (1986 to 2015) in the Sustainable Development Reserve Nascentes das Geraizeiras (SDR-NG) and a $10 \mathrm{~km}$ buffer zone in the state of Minas Gerais. The effects of deforestation on native vegetation fragmentation were also evaluated using remotely sensed data and landscape analysis. This study indicates that deforestation affected more than half of the native vegetation by 2015 , which affected the integrity of native vegetation fragments in the entire study area. The SDR-NG contributed to mitigating the fragmentation of natural vegetation that occurred around that Reserve because of a secondary regrowth observed in some previously degraded areas. It was observed that the most significant environmental threat to that Reserve is fire events, which vary annually in extent and socio-environmental damages. The land sustained use in the SDR-NG could be improved by expanding sustainable economic activities, such as using non-timber forest products, the implementation of agroforestry systems, and other economic activities moderately. These practices will ensure the maintenance of natural resources, economic production, increase income and labor opportunities to local communities, and include all social segments and populations living within and around that Reserve.

Keywords: Protected Areas; Landscape analysis; Cerrado

\section{INTRODUÇÃO}

A substituição das paisagens naturais por diversos tipos de usos da terra e, sobretudo, pelos modelos econômicos exploratórios dos recursos naturais e os diferentes ciclos de crescimento e dispersão populacional, têm contribuído com o aumento da fragmentação florestal (RIBEIRO et al., 2009; TABARELLI et al., 2010), alterando a paisagem natural, resultando, como consequência, em mais fragmentos florestais de menor tamanho, geralmente inseridos dentro de uma matriz de habitat não florestais (TABARELLI; GASCON, 2005).

A fragmentação da vegetação natural no norte de Minas Gerais foi causada essencialmente pela ação humana, com a conversão de áreas nativas em áreas de pastagens. Entretanto, a ampliação de áreas plantadas com eucaliptos também se destacou nesta região, ocupando extensas áreas com maciços de monocultura de eucalipto (MAGALHÃES; AMORIM, 2015) para produção de carvão para siderurgia, as terras mais baratas encontradas especialmente nos municípios de Buritizeiro e Rio Pardo de Minas (LEITE; ALMEIDA; SILVA, 2012; MAGALHÃES; AMORIM, 2015). 
A introdução da monocultura de eucaliptos na região das Geraizeiras, norte do estado de Minas Gerais, provocou uma série de conflitos fundiários entre as comunidades tradicionais e as empresas florestais e, mais recentemente, com as mineradoras de ferro. A região é predominantemente ocupada por terras consideradas "devolutas" que terminam em uma disputa entre as comunidades locais e a grilagem de terras devido à sobreposição e imprecisão nos limites das propriedades rurais (MAGALHÃES; AMORIM, 2015).

Os processos desordenados de ocupação de terra e, principalmente, o uso intensivo dos recursos naturais, são as principais causas da preocupação com o meio ambiente. E, com isso, há um aumento da demanda relacionada ao conhecimento das características ambientais regionais, permitindo conhecer a composição básica dos conjuntos paisagísticos e aspectos da fauna e da flora de uma região (CARVALHO; CARVALHO, 2012).

Nesse contexto, os dados de mapeamentos temáticos com dados de sensoriamento remoto permitem, a partir de técnicas utilizando métricas da paisagem, compreender melhor as mudanças das paisagens quantificando suas estruturas (PANG et al., 2010; ZARAGOZÍ et al., 2012). Tais métricas derivam índices que descrevem o nível de uniformidade ou fragmentação espacial de uma paisagem, calculados a partir de métricas de área, forma, borda, área do núcleo, proximidade, isolamento, contraste, contágio e diversidade, dentre outros (MCGARIGAL; MARKS, 1995).

No presente estudo buscou-se entender melhor as mudanças do uso e cobertura da terra no período entre 1986 a 2015 na Reserva de Desenvolvimento Sustentável Nascentes das Geraizeiras (RDS-NG) e no seu entorno, utilizando dados e técnicas de sensoriamento remoto, e analisar a estrutura da paisagem quanto ao padrão de fragmentação, a partir do uso de métricas da paisagem da cobertura vegetal natural remanescente. Assim, as questões que nortearam esta pesquisa foram: qual a dinâmica de uso e cobertura da terra entre 1986 e 2015 na área de estudo? Quais os efeitos do desmatamento na fragmentação da paisagem? Quais as tendências futuras do desmatamento na região? 


\section{MATERIAIS E MÉTODOS}

\subsection{Localização e caracterização da área de estudo}

A Reserva de Desenvolvimento Sustentável Nascentes das Geraizeiras é uma Unidade de Conservação (UC) de uso sustentável, criada pelo Decreto Federal sem número de 13 de outubro de 2014. Localizada no Norte de Minas Gerais, Brasil, abrangendo os municípios de Rio Pardo de Minas, Montezuma e Vargem Grande do Rio Pardo, com uma área de 38.177 hectares.

A RDS-NG está geograficamente situada nas coordenadas 15030' de latitude Sul e $42^{\circ} 40^{\prime}$ de longitude Oeste, no norte de Minas Gerais. A área possui, como componente principal da flora, o bioma Cerrado em suas várias fisionomias. No presente estudo de uso e ocupação do solo foi adotada uma zona de $10 \mathrm{~km}$ no entorno do limite legal da RDS-NG, abrangendo um adicional de 155.459 hectares, que envolve uma área mais ampla do que a distância mínima de 3 km definida pela Resolução do Conselho Nacional do Meio Ambiente (CONAMA) n 428/10, de 17 de dezembro de 2010 (BRASIL, 2010) como zona de amortecimento para Unidades de Conservação sem plano de manejo. Optou-se por uma zona de $10 \mathrm{~km}$ no entorno da Reserva para captar de forma mais ampla os efeitos da fragmentação e a integridade da paisagem no entorno que afetam o interior da RDS-NG. Com isso, o presente estudo (RDS + zona de $10 \mathrm{~km}$ no entorno) envolveu uma área total de 193.636 hectares (Figura 1).

A vegetação presente na região se caracteriza pela presença dos biomas Cerrado e Caatinga e áreas de transição, com fitofisionomias predominantes de Cerrado, Campo Cerrado, Floresta Estacional Decidual Montana, Vereda e Floresta Estacional Decidual Sub Montana (SCOLFORO; CARVALHO, 2006). A RDS-NG é drenada pela bacia do rio Pardo (EUCLYDES, 2007).

O clima predominante na área de estudo é o tropical semiúmido com manchas de semiaridez, com duas estações definidas uma estação úmida e uma estação seca (SANTOS; LOUZADA; EUDENIO, 2010). Os solos são do tipo Cambissolos, Latossolos Vermelho-Amarelo, há também a presença de Litossolos e solos Aluviais. 
O uso da terra predominante praticado pelas comunidades locais dos geraizeiros é o extrativismo vegetal de espécies do cerrado e a criação de gado no sistema extensivo, em pastagens plantadas e naturais. Associado a isso, existem áreas de propriedade privada dedicada à criação de gado em pastagens plantadas e ao plantio de eucaliptos (MAGALHÃES; AMORIM, 2015).

Figura 1 - Localização da Reserva de Desenvolvimento Sustentável (RDS) Nascentes das Geraizeiras e da zona de $10 \mathrm{~km}$ no seu entorno no norte do estado de Minas Gerais, Brasil

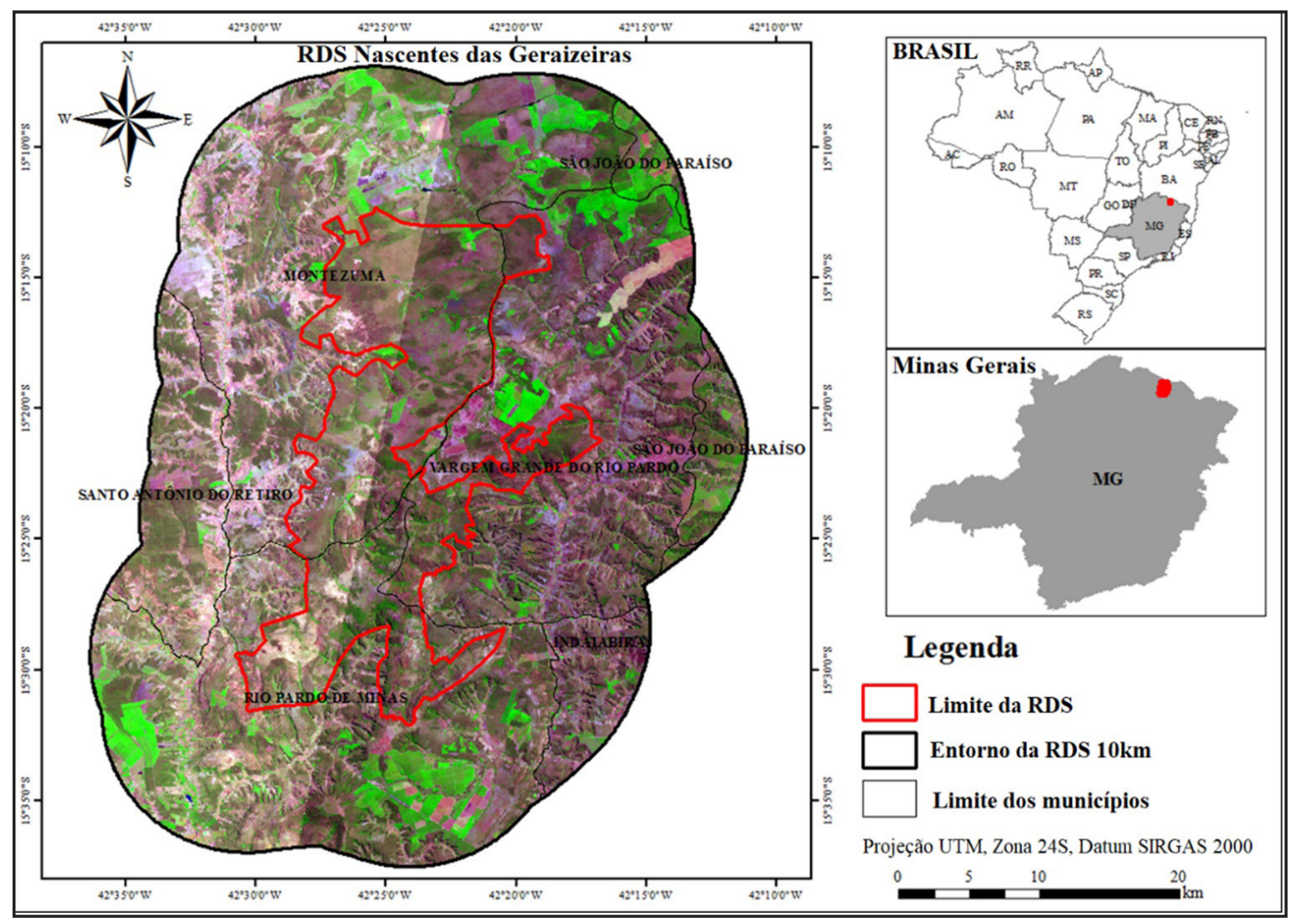

Fonte: Autores (2020)

\subsection{Base de dados}

As análises do uso e cobertura da terra na área de estudo foram baseadas em imagens dos satélites Landsat-5 sensor TM (Thematic Mapper), cenas órbita/ponto 217/71, 218/70 e 218/71 com resolução espacial de 30 m, bandas espectrais 2, 3, 4, 5 e 
7 e Landsat-8 sensor OLI (Operational Land Imager), cenas órbita/ponto 217/71, 218/70 e 218/71 com resolução espacial de 30 m, bandas espectrais 2, 3, 4,5, 6 e 7, entre os anos de 1986, 1996, 2006, e 2015 (Tabela 1). As imagens Landsat foram obtidas do Serviço Geológico Americano (USGS) (UNITED STATES, 2014), disponível na rede mundial de computadores (Internet).

Tabela 1 - Cenas Landsat (Órbita/Ponto) utilizadas neste estudo

\begin{tabular}{lcccc}
\hline \multirow{2}{*}{ Órbita/ponto } & \multicolumn{4}{c}{ Satélites / Sensor } \\
\cline { 2 - 5 } & Landsat-5 TM & Landsat-5 TM & Landsat -5 TM & Landsat -8 OLI \\
\cline { 2 - 5 } & $\mathbf{1 9 8 6}$ & $\mathbf{1 9 9 6}$ & $\mathbf{2 0 0 6}$ & $\mathbf{2 0 1 5}$ \\
\hline $217 / 71$ & $11 /$ Outubro & 18/Outubro & 30/Julho & 09/Setembro \\
$218 / 70$ & 18/Outubro & 10/Agosto & 21/Julho & 02/Outubro \\
$218 / 71$ & 18/Outubro & 10/Agosto & 21/Julho & 02/Outubro \\
\hline
\end{tabular}

Fonte: Autores (2020)

\subsection{Processamento das imagens de satélite}

O processamento digital das imagens foi conduzido com o uso do software ArcGIS $^{\circledR}$ 10.6, licenciado pela empresa ESRI para uso institucional (acadêmico e pesquisa) na Universidade de Brasília. Inicialmente, fez-se a composição das bandas $(1,2,3,4,5$ e 7) para as imagens do satélite Landsat 5, sensor TM (Thematic Mapper), e das bandas (2 a 7) para as imagens do satélite Landsat 8, sensor OLI (Operational Land Imager). Na sequência, todas as cenas Landsat foram corrigidas geometricamente (georreferenciamento) utilizando como base cartográfica a rede viária e rede hidrográfica da região de estudo. Adotou-se o sistema de coordenadas UTM, Zona 24 Sul, Datum WGS-84, para as imagens da órbita/ponto 217/71 e o sistema de coordenadas UTM, Zona 23 Sul, Datum WGS-84 para as imagens da órbita/ponto 218/70 e 218/71. Originalmente, as imagens da órbita 217 e 217 da série Landsat 5 e 8, estão localizadas em Zonas UTM diferentes. Após o georreferenciamento das imagens Landsat, foi montado um mosaico das cenas órbita 218, pontos 70 e 71, mantendo a Zona UTM 
23 Sul. A classificação do uso e cobertura da terra foi aplicada separadamente sobre o mosaico das cenas 218/70 e 71 e a cena 217/71 para reduzir os efeitos da sazonalidade observadas nas imagens. Uma vez classificadas, inspecionadas e editadas visualmente, as classificações do uso e cobertura formam mosaicadas, adotando-se a Zona UTM 23 S, na qual está inserida a maior parte da RDS-NG.

Fez-se um recorte para a área deste estudo e da zona de $10 \mathrm{~km}$ no seu entorno, a fim de reduzir o tempo de processamento das imagens. As observações visuais preliminares foram feitas sobre as imagens na composição colorida RGB 5/4/3 das bandas do Landsat-5 e RGB 6/5/4 das bandas do Landsat-8, correspondentes às faixas espectrais do infravermelho médio, infravermelho próximo e vermelho, respectivamente. Essa composição colorida das bandas das imagens Landsat permite inspeções visuais preliminares de alvos em terras emersas com cores tipicamente reconhecidas pela visão humana (MENESES; ALMEIDA, 2012).

O mapeamento de uso e cobertura da terra foi realizado pelo método de classificação supervisionada, algoritmo de Máxima Verossimilhança (MaxVer). Na sequência, foram delimitadas amostras (áreas de treinamento) sobre cada imagem, para obtenção da assinatura espectral para as feições de interesse (área queimada, reflorestamento, vegetação nativa, áreas antropizadas e corpos d'água), a partir do conhecimento prévio que se teve da área durante visitas de campo no mês de março de 2015 e da utilização de uma imagem de alta resolução espacial (5 metros) satélite RapidEye, com 5 bandas espectrais (azul, verde, vermelho, vermelho limítrofe e infravermelho próximo), adquirida em agosto de 2014.

\subsection{Avaliação da acurácia}

A avaliação da acurácia foi realizada para avaliar a qualidade da classificação do mapeamento, utilizando as cenas das imagens Landsat-8, órbita/ponto 218/70, 218/71 e $217 / 71$. Nessa etapa foram seguidos os mesmos "procedimentos metodológicos de classificação adotados para todas as cenas das imagens anteriormente citadas, 
gerando uma matriz de erros (matriz de confusão) do método de classificação digital. Para isso, foram distribuídos 260 pontos amostrais aleatórios. Para cada ponto aleatorizado foi feita a verificação visual da feição classificada e da observada em imagem de alta resolução (5 metros) adquirida pelo satélite RapidEye.

A estimativa da acurácia total, da acurácia do usuário (relacionada aos erros de omissão ou subestimativa da classificação) e da acurácia do produtor (relacionada aos erros de comissão ou superestimativas da classificação) possibilitou a avaliação dos erros de superestimação e subestimação gerados pelo classificador. Estimou-se também o índice Kappa e, como referência para os resultados obtidos na matriz de confusão, foi utilizada a classificação sugerida por Landis e Koch (1977) (Tabela 2).

Tabela 2 - Parâmetros do coeficiente Kappa

\begin{tabular}{lc}
\hline \multicolumn{1}{c}{ Coeficiente Kappa } & Exatidão \\
\hline$<0$ & Péssima \\
$0<\mathrm{k} \leq 0,2$ & Ruim \\
$0,2<\mathrm{k} \leq 0,4$ & Razoável \\
$0,4<\mathrm{k} \leq 0,6$ & Boa \\
$0,6<\mathrm{k} \leq 0,8$ & Muito Boa \\
$0,8<\mathrm{k} \leq 1,0$ & Excelente \\
\hline
\end{tabular}

Fonte: Landis e Koch (1997)

\subsection{Avaliação da dinâmica espaço temporal de uso e cobertura da terra}

A partir dos mapas de uso da terra gerados realizou-se a análise da dinâmica temporal da cobertura florestal remanescente, na qual foram estimadas as classes de vegetação nativa em quatro períodos: 1986-1996, 1996-2006, 2006-2015 e 1986-2015, este último correspondente a todo o período de estudo.

A dinâmica florestal foi realizada a partir dos dados organizados sob a análise de áreas obtidas para cada dois períodos. Assim, foram avaliadas a vegetação preservada (as áreas que no período inicial estavam cobertas por vegetação de Cerrado/mata ciliar e no período posterior da análise permaneceram cobertas por Cerrado/mata ciliar), as 
áreas antropizadas (as áreas que no primeiro período de análise estavam cobertas por vegetação nativa - Cerrado, mata ciliar e corpos d'água - e no final estavam compostas por áreas antropizadas - área queimada e solo alterado) e a regeneração (quando as classes: áreas antropizadas, áreas queimadas e reflorestamento identificadas na data inicial foram convertidas em classes de vegetação nativa ou mata ciliar). O cruzamento dos quatro períodos de análise 1986-1996, 1996-2006 e 2006-2015 foi feito a partir dos dados da dinâmica da cobertura florestal no software $\operatorname{ArcGIS}^{\circledR}$ versão 10.6, com uma licença corporativa do ESRI (Environmental Systems Research Institute) para a Universidade de Brasília.

\subsection{Análise da fragmentação florestal}

A análise da fragmentação também foi conduzida a partir dos mapas temáticos gerados. Para esta etapa do estudo, as classes originais de uso e cobertura da terra foram reclassificadas (agrupadas) em duas classes: vegetação (vegetação nativa e reflorestamento) e não vegetação (áreas queimadas, agricultura e corpos d'água), com o enfoque da análise na fragmentação da vegetação nativa. No presente estudo, considerou-se que os reflorestamentos contribuem com a conservação dos fragmentos de vegetação nativa, mitigando os efeitos de bordadura e da ocorrência de incêndios florestais (VIANA; PINHEIRO, 1998).

Para descrever o nível de fragmentação da paisagem natural na RDS-NG, foi utilizado o software Fragstats $^{\circledR}$ versão 4.2, desenvolvido na Universidade de Massachusetts, Estados Unidos da América, de acesso gratuito na rede mundial Internet (MCGARIGAL; CUSHMAN; ENE, 2012). Para o cálculo das métricas da paisagem foram selecionados índices que possibilitaram quantificar os elementos da paisagem, estimando assim a área, a densidade, a forma, a área central, a proximidade e o isolamento, o contágio e a dispersão e a diversidade (MCGARIGAL; CUSHMAN; ENE, 2012). As métricas geradas pelo software Fragstats ${ }^{\circledR}$ estão descritas na Tabela 3. 
Tabela 3 - Métricas espaciais utilizadas para estimar a estrutura da paisagem da área de estudo

\begin{tabular}{|c|c|c|}
\hline Grupo & Métrica & Sigla \\
\hline \multirow{4}{*}{ Área e densidade } & Número de fragmentos (adimensional) & NP \\
\hline & Área do maior fragmento (\%) & LPI \\
\hline & $\begin{array}{l}\text { Porcentagem de fragmentos de mesma classe na } \\
\text { paisagem (\%) }\end{array}$ & PLAND \\
\hline & Área média dos fragmentos (hectares) & AREA_MN \\
\hline \multirow{3}{*}{ Forma } & Índice de forma médio (adimensional) & SHAPE_MN \\
\hline & $\begin{array}{l}\text { Dimensão fractal média } \\
\qquad(1 \leqq \text { FRAC } \leqq 2)\end{array}$ & FRAC_MN \\
\hline & $\begin{array}{l}\text { Círculo circunscrito relacionado médio } \\
\qquad(0<\mathrm{CIRCLE}<1)\end{array}$ & CIRCLE_MN \\
\hline \multirow{3}{*}{ Área Central } & Número de áreas centrais disjuntas (adimensional) & NDCA \\
\hline & Índice de área central médio (\%) & CAI_MN \\
\hline & $\begin{array}{c}\text { Porcentagem da área do núcleo relativamente à } \\
\text { paisagem (\%) }\end{array}$ & CPLAND \\
\hline $\begin{array}{l}\text { Proximidade e } \\
\text { isolamento }\end{array}$ & Proximidade média entre classes (categorias) & PROX_MN \\
\hline Contágio e dispersão & Conectividade (\%) & COHESION \\
\hline \multirow{2}{*}{ Diversidade } & $\begin{array}{l}\text { Índice de diversidade de Shannon } \\
\qquad(S H D I \geq 0)\end{array}$ & SHDI \\
\hline & $\begin{array}{l}\text { Índice de Uniformidade de Shannon } \\
\qquad(0 \leq S H E I \leq 1)\end{array}$ & SHEI \\
\hline
\end{tabular}

Fonte: Adaptado de McGarigal e Marks (1995)

\section{RESULTADOS E DISCUSSÃO}

\subsection{Acurácia da classificação do uso e cobertura da terra}

A performance da classificação supervisionada do uso e cobertura da terra para os anos estudados, a partir da matriz de confusão estimada, indicam uma acurácia global de 98\% para todas as classes adotadas neste estudo. Esse resultado de acurácia global é considerado uma excelente classificação (GUPTILL; MORRISON, 1995). Estimouse também um coeficiente Kappa de 46\%, que confirma o bom desempenho global 
da classificação (LANDIS; KOCH, 1977; QUEIROZ; GOMES, 2006). A Tabela 4 mostra de forma mais detalhada os resultados da matriz de confusão gerada neste estudo.

Tabela 4 - Matriz de confusão da classificação do uso e cobertura da terra para 2014 usando cena do satélite RapidEye de 2014 e checagem de campo como referência para avaliar a classificação das imagens

\begin{tabular}{|c|c|c|c|c|c|c|c|}
\hline \multirow[b]{2}{*}{$\begin{array}{c}\text { Classificação } \\
\text { (Landsat - 8, 2014) }\end{array}$} & \multicolumn{7}{|c|}{ Imagem Referência - RapidEye (2014) } \\
\hline & Reflorestamento & $\begin{array}{c}\text { Áreas } \\
\text { Antropizadas }\end{array}$ & $\begin{array}{l}\text { Vegetação } \\
\text { Nativa }\end{array}$ & $\begin{array}{l}\text { Corpos } \\
\text { D'água }\end{array}$ & $\begin{array}{c}\text { Pontos } \\
\text { Amostrados }\end{array}$ & $\begin{array}{l}\text { Acurácia } \\
\text { Usuário }\end{array}$ & $\begin{array}{l}\text { Erros de } \\
\text { Comissão }\end{array}$ \\
\hline Reflorestamento & 75 & 0 & 0 & 0 & 75 & $100 \%$ & $0 \%$ \\
\hline Áreas Antropizadas & 2 & 54 & 2 & 0 & 58 & $93 \%$ & $7 \%$ \\
\hline Vegetação Nativa & 0 & 0 & 81 & 0 & 81 & $100 \%$ & $0 \%$ \\
\hline Corpos D'água & 0 & 0 & 0 & 46 & 46 & $100 \%$ & $0 \%$ \\
\hline $\begin{array}{l}\text { Pontos amostrados } \\
\text { por classe de uso da } \\
\text { terra }\end{array}$ & 77 & 54 & 83 & 46 & 260 & & \\
\hline Acurácia Produtor & $97 \%$ & $100 \%$ & $98 \%$ & $100 \%$ & & & \\
\hline Erros de Omissão & $3 \%$ & $0 \%$ & $2 \%$ & $0 \%$ & & & \\
\hline
\end{tabular}

Fonte: Autores (2020)

\subsection{Avaliação da dinâmica de uso e cobertura da terra}

Os resultados do mapeamento da dinâmica do uso e cobertura da terra entre 1986 e 2015 indicam um aumento de 65\% das áreas antropizadas na zona 10 km no entorno da RDS-NG, e de 11\% dentro da RDS. As áreas atingidas por fogo dentro e no entorno da RDS oscilaram fortemente durante o período estudado, ocorrendo, predominantemente, em 1986 e 2015. Essa oscilação indica que variações climáticas ocorridas nos anos de análise foram decisivas no aumento ou redução da predisposição da vegetação local ao fogo. No período de estudo, verificou-se a redução de 66\% e 45\% das áreas plantadas com eucaliptos dentro e no entorno da RDS-NG, respectivamente. As áreas de vegetação nativa aumentaram 6\% dentro da RDS e reduziram 7,2\% no entorno da RDS entre 1986 e 2015. 
As Tabelas 5 e 6 apresentam os resultados da classificação do uso e cobertura da terra no período de análise para a RDS e a zona de $10 \mathrm{~km}$ de seu entorno, respectivamente.

Tabela 5 - Mudanças no uso e cobertura da terra dentro da RDS-NG entre 1986 e 2015

\begin{tabular}{|c|c|c|c|c|c|c|c|c|}
\hline \multirow{3}{*}{$\begin{array}{c}\text { Uso e Cobertura } \\
\text { da Terra }\end{array}$} & \multicolumn{8}{|c|}{ Área } \\
\hline & \multicolumn{2}{|c|}{1986} & \multicolumn{2}{|c|}{1996} & \multicolumn{2}{|c|}{2006} & \multicolumn{2}{|c|}{2015} \\
\hline & Área (há) & $\%$ & Área (ha) & $\%$ & Área (ha) & $\%$ & Área (ha) & $\%$ \\
\hline Área Queimada & $3.966,0$ & 10,4 & 193,0 & 0,5 & 47,0 & 0,1 & $2.570,0$ & 6,7 \\
\hline Reflorestamento & $1.758,0$ & 4,6 & $4.846,0$ & 12,7 & 829,0 & 2,2 & 605,0 & 1,6 \\
\hline Áreas antropizadas & $10.954,0$ & 28,7 & $14.348,0$ & 37,6 & $11.862,0$ & 31,1 & $12.176,0$ & 31,9 \\
\hline Vegetação nativa & $21.495,0$ & 56,3 & $18.709,0$ & 49,0 & $25.434,0$ & 66,6 & $22.796,0$ & 59,7 \\
\hline Corpos D'água & 4,0 & 0,0 & 81,0 & 0,2 & 5,0 & 0,0 & 30,0 & 0,1 \\
\hline Total & $38.177,0$ & 100,0 & $38.177,0$ & 100,0 & $38.177,0$ & 100,0 & $38.177,0$ & 100,0 \\
\hline
\end{tabular}

Fonte: Autores (2020)

Tabela 6 - Mudanças no uso e cobertura da terra no entorno (zona de 10 km) da RDSNG entre 1986 e 2015

\begin{tabular}{|c|c|c|c|c|c|c|c|c|}
\hline \multirow{3}{*}{$\begin{array}{c}\text { Uso e Cobertura } \\
\text { da Terra }\end{array}$} & \multicolumn{8}{|c|}{ Área } \\
\hline & \multicolumn{2}{|c|}{1986} & \multicolumn{2}{|c|}{1996} & \multicolumn{2}{|c|}{2006} & \multicolumn{2}{|c|}{2015} \\
\hline & Área (ha) & $\%$ & Área (ha) & $\%$ & Área (ha) & $\%$ & Área (ha) & $\%$ \\
\hline Área Queimada & 11.974 & 7,7 & 511 & 0,3 & 502 & 0,3 & 12.015 & 7,7 \\
\hline Reflorestamento & 26.042 & 16,7 & 17.485 & 11,2 & 7.779 & 5 & 14.318 & 9,2 \\
\hline Áreas antropizadas & 35.094 & 22,6 & 65.599 & 42,2 & 56.917 & 36,6 & 57.946 & 37,3 \\
\hline Vegetação nativa & 82.313 & 52,9 & 71.803 & 46,2 & 90.248 & 58 & 71.082 & 45,7 \\
\hline Corpos D’água & 125 & 0,1 & 151 & 0,1 & 103 & 0,1 & 187 & 0,1 \\
\hline Total & 155.549 & 100 & 155.549 & 100 & 155.549 & 100.0 & 155.549 & 100 \\
\hline
\end{tabular}

Fonte: Autores (2020)

As alterações na paisagem natural na região do entorno da RDS-NG ocorreram predominantemente em áreas de relevo plano e levemente ondulado. Essas áreas foram definidas por Correia (2005) como a região da "baixada", mais próximas aos corpos d'água, onde havia solos com maior aptidão para os diversos usos antrópicos, principalmente a agricultura e a pecuária. 
Leite, Almeida e Silva (2012) analisaram a dinâmica do eucalipto no Norte de Minas Gerais entre 1986 e 2010. Os autores constataram a diminuição das áreas reflorestadas com esta espécie florestal no período analisado. Após 1996, vários fatores podem ter levado ao declínio do plantio de eucalipto na região. Destaca-se o maior rigor na implementação das leis de licenciamento ambientais, que dificultou a instalação de novas áreas de plantio (VELOSO; LEITE, 2013). É possível que as áreas destinadas ao plantio de espécies florestais tenham migrado para outras regiões mais viáveis social, econômica e ambientalmente.

As observações de campo realizadas neste estudo indicam que a maior parte da área de vegetação nativa desmatada no entorno da RDS-NG foi convertida em pastagens para as atividades agropecuárias. Dentro dos limites da RDS, as pastagens se expandiram sobre áreas de reflorestamento no período de estudo. Souza et al. (2014) observaram que as atividades agropastoris foram as principais responsáveis pelo aumento da fragmentação da paisagem numa área de estudo na região de Coqueiral, estado de Minas Gerais. Observou-se ainda que algumas áreas de reflorestamento detectadas em 1986 e 1996 foram regeneradas e contribuíram para aumentar o percentual de vegetação nativa dentro da RDS.

As áreas com cicatrizes de fogo ocupavam 7,7\% da área do entorno da RDS e 10,4\% da RDS em 1986. Nesse período não existiam políticas eficazes de prevenção e combate aos incêndios florestais no Estado, somente a partir de 2008 houve uma ampliação e eficácia no combate aos incêndios (INSTITUTO ESTADUAL DE FLORESTAS, 2014).

As áreas ocupadas com corpos d'água na região de estudo estão associadas principalmente aos corpos hídricos naturais e ao represamento (lagos artificiais) destinados principalmente à dessedentação de animais. Essa classe ocupou uma parte inexpressiva da paisagem, tanto no entorno quanto dentro da RDS-NG, mantendo-se estável em todos os anos de análise. No entanto, há relatos de moradores da RDS- 
NG de que foi observada a redução da quantidade de água dos rios temporários e perenes nos anos mais recentes, provavelmente como consequência da ampliação do desmatamento na região de estudo. A Figura 2 apresenta mais detalhes da distribuição espacial das mudanças.

Figura 2 - Uso e cobertura da terra na área de estudo (RDS-NG e zona de entorno $10 \mathrm{~km})$ em 1986, 1996, 2006 e 2015

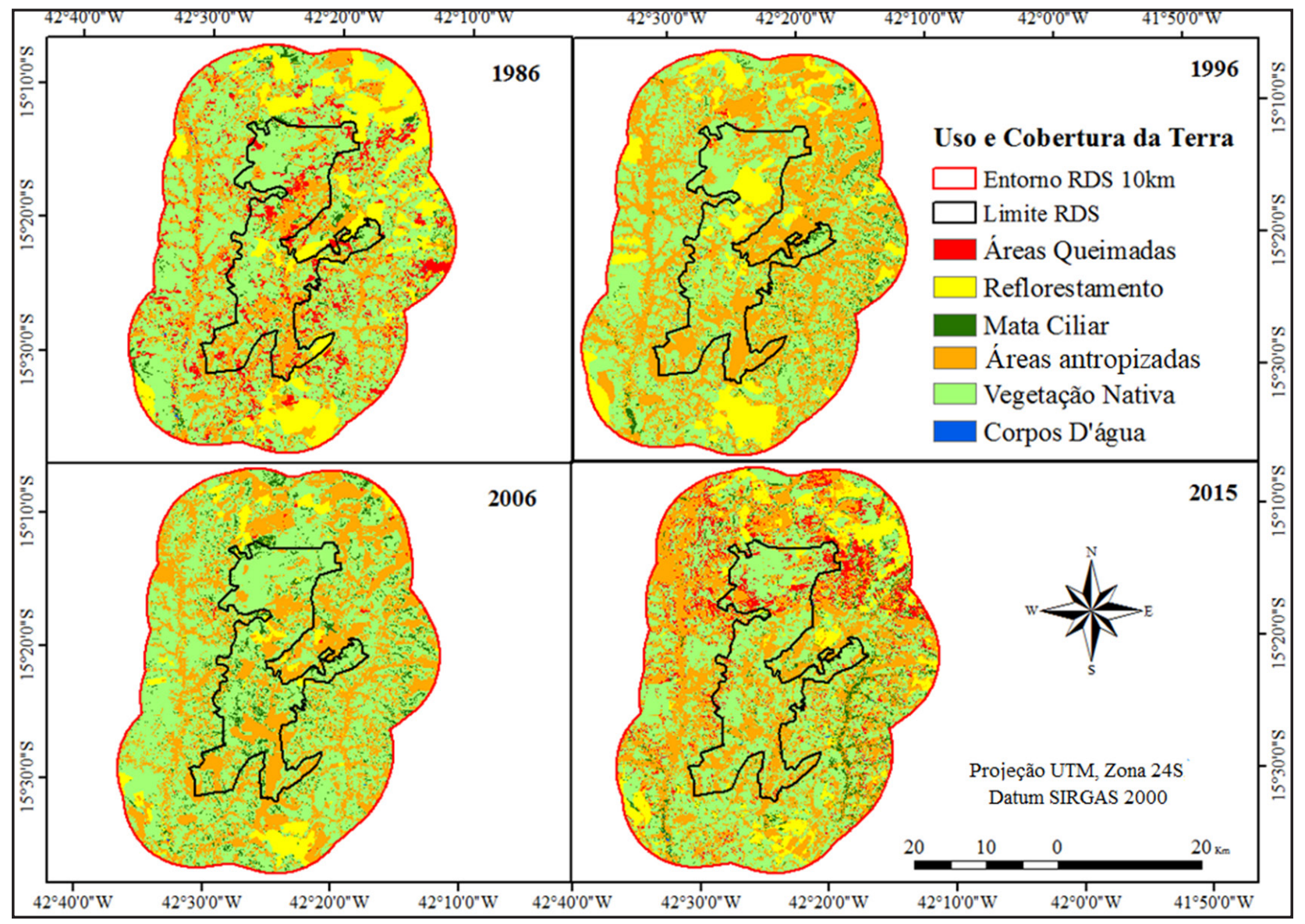

Fonte: Autores (2020)

Nas Tabelas 7 e 8 e na Figura 3, são apresentados os detalhes da dinâmica do uso e cobertura da terra nos períodos de estudo 1986-1996, 1996-2006, 2006-2015 e 19862015, com a variação percentual em área de vegetação nativa, a regeneração natural e as áreas antropizadas (agricultura e pastagens plantadas). A vegetação nativa e as áreas de regeneração natural apresentaram variações e áreas antropizadas apresentaram 
acréscimo nos quatro períodos analisados em ambas as áreas, no entorno da RDS e dentro da RDS. Destaca-se a variação da ocorrência das áreas queimadas na área de estudo, que é bastante influenciada pelas condições climáticas e prática do uso do fogo como técnica de manejo em áreas de pastagens e agricultura.

Tabela 7 - Mudanças do uso e cobertura da terra nos períodos de 1986-1996, 19962006, 2006-2015 e 1986-2015 na RDS-NG

\begin{tabular}{|c|c|c|c|c|c|c|c|c|}
\hline & \multicolumn{2}{|c|}{ 1986-1996 } & \multicolumn{2}{|c|}{ 1996-2006 } & \multicolumn{2}{|c|}{ 2006-2015 } & \multicolumn{2}{|c|}{ 1986-2015 } \\
\hline & Área (ha) & $\%$ & Área (ha) & $\%$ & Área (ha) & $\%$ & Área (ha) & $\%$ \\
\hline Vegetação nativa & $15.389,5$ & 40,27 & $19.754,4$ & 51,69 & $17.452,4$ & 45,66 & $17.232,6$ & 45,09 \\
\hline Regeneração natural & $3.337,3$ & 8,73 & $7.897,9$ & 20,66 & $3.080,0$ & 8,06 & $5.564,7$ & 14,56 \\
\hline Antropizadas** & $14.473,6$ & 37,87 & $11.866,9$ & 31,05 & $14.709,7$ & 38,49 & $14.683,4$ & 38,42 \\
\hline
\end{tabular}

Fonte: Autores (2020)

Em que: (*) Percentagens em relação à área total da região de estudo (38.177 hectares); (**) A classe "Antropizadas" se refere ao agrupamento das áreas de pastagens plantadas e agricultura.

Tabela 8 - Mudanças do uso e cobertura da terra nos períodos de 1986-1996, 19962006, 2006-2015 e 1986-2015 no entorno (zona de 10 km) da RDS-NG

\begin{tabular}{|c|c|c|c|c|c|c|c|c|}
\hline & \multicolumn{2}{|c|}{ 1986-1996 } & \multicolumn{2}{|c|}{$1996-2006$} & \multicolumn{2}{|c|}{ 2006-2015 } & \multicolumn{2}{|c|}{$1986-2015$} \\
\hline & Área (ha) & $\%$ & Área (ha) & $\%$ & Área (ha) & $\%$ & Área (ha) & $\%$ \\
\hline Vegetação nativa & $58.007,40$ & 37,29 & $64.951,80$ & 41,76 & $60.344,9$ & 38,79 & $52.937,9$ & 34,03 \\
\hline Regeneração natural & 13.785 & 8,86 & $25.066,50$ & 16,11 & 10.918 & 7,02 & $18.118,6$ & 11,65 \\
\hline Antropizadas ** & $65.934,50$ & 42,39 & $57.554,40$ & 37,00 & $69.936,5$ & 44,96 & 69.794 & 44,87 \\
\hline
\end{tabular}

Fonte: Autores (2020)

Em que: (*) Percentagens em relação à área total da região de estudo (155.549 hectares); (**) A classe "Antropizadas" se refere ao agrupamento das áreas de pastagens plantadas e agricultura.

As estimativas dos diferentes tipos de uso e cobertura da terra, especialmente a agricultura e pecuária, indicam a redução da vegetação nativa na área do entorno e a estabilidade dentro da RDS-NG no período de 1986 a 2015. Esse resultado revela que há uma pressão antrópica eminente no entorno da RDS que requer medidas para evitar a descaracterização dos objetivos da criação desta Unidade de Conservação. 
A regeneração da vegetação nativa teve o maior incremento entre 1996 e 2006 na área de estudo. Esse aumento pode ser explicado pela redução dos plantios de eucalipto, que foram convertidos para agricultura ou pecuária e, em alguns casos, pela regeneração secundária da vegetação local.

Figura 3 - Dinâmica do uso e cobertura da terra entre 1986 e 1996, 1996 e 2006, 2006 e 2015 e 1986 e 2015, na área do entorno e dentro da RDS-NG

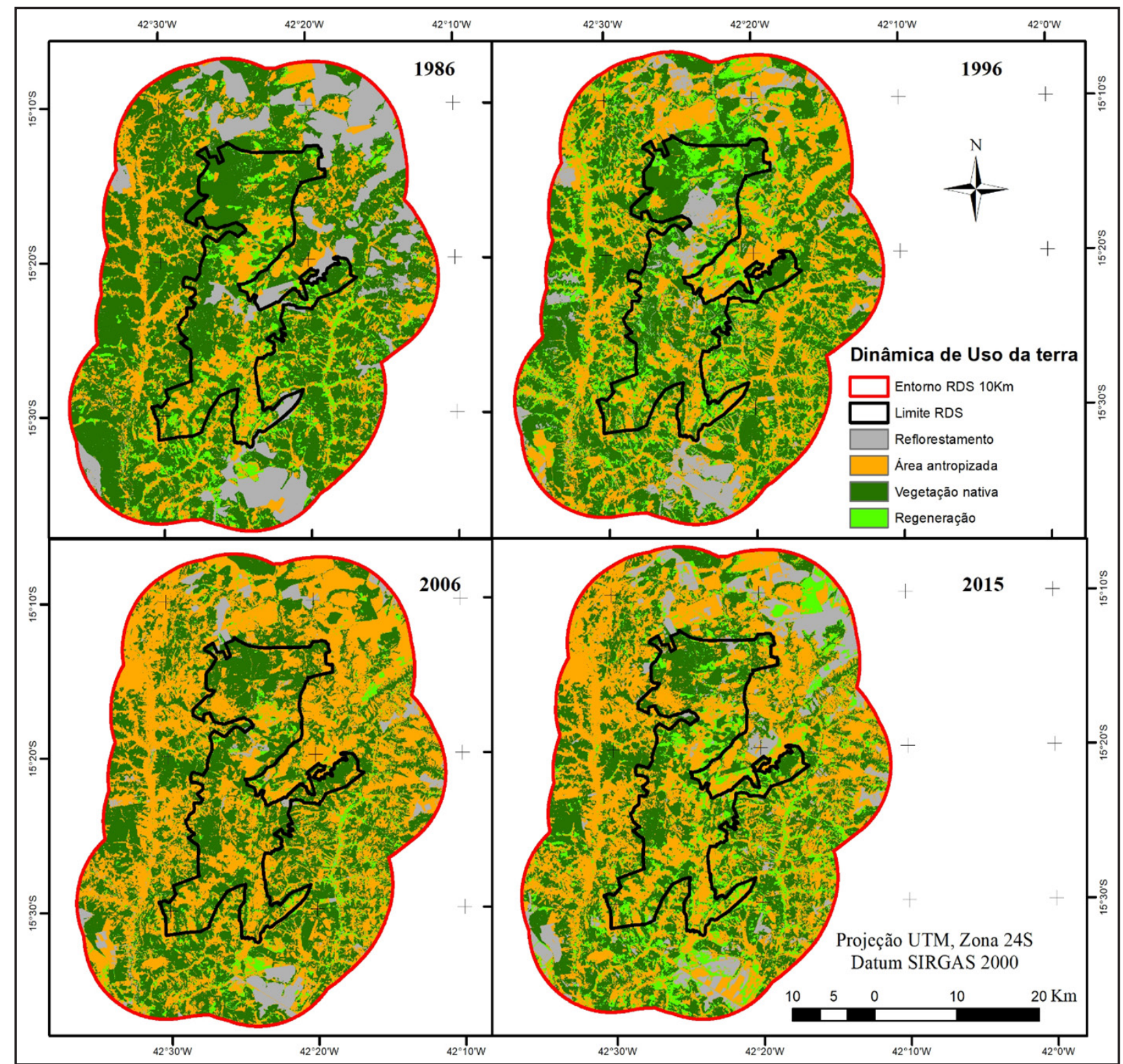

Fonte: Autores (2020)

As áreas de solos alterados tiveram um incremento de 42,3\% e 37,9\% no entorno 
e dentro da RDS-NG, respectivamente, entre 1986 e 1996. Na década seguinte (1996 a 2006), as áreas de solos alterados foram reduzidas em toda área de estudo. Entre 2006 e 2015, as áreas de solos alterados aumentaram aproximadamente 45\% e 39\% na área do entorno e dentro da RDS, respectivamente, ocupando também algumas áreas previamente ocupadas por cultivo de eucaliptos. Leite, Almeida e Silva (2012) explicam que, a partir de 2010, as áreas que foram ocupadas pela monocultura de eucalipto em 1986 e 1996 deixaram de ser utilizadas para esse fim e foram convertidas para fins agropecuário ou abandonadas.

\subsection{Cálculo das métricas da paisagem da vegetação natural}

Os resultados das métricas de áreas e densidade indicam que a porcentagem da paisagem (PLAND), ocupada por maiores fragmentos de vegetação nativa, aumentou tanto dentro da RDS-NG quanto na área de seu entorno, sendo mais expressivos para o interior da RDS em todo o período de estudo (de 1986 a 2015) do que para o seu entorno. Contudo, ambas as áreas obtiveram valores mais elevados no último ano de estudo (2015), indicando melhoria na composição da paisagem natural, favorecendo sua conservação, pois corresponde à classe de maior cobertura da paisagem (MCGARIGAL et al., 2002).

O maior fragmento de vegetação nativa (LPI), denominado matriz, apresentou um aumento substancial no interior da RDS-NG e em seu entorno de 63\% e 22\%, respectivamente, entre 1996 e 2015. O incremento observado em LPI indica que a paisagem natural estava mais fragmentada (MCGARIGAL; MARKS, 1995) em 1986 quando comparada com os demais anos seguintes desta análise. Quanto maior o valor desse índice, melhor serão as condições para os dispersores, polinizadores e propágulos, abastecendo fragmentos menores com a criação de condições favoráveis para a manutenção da biodiversidade local (MCGARIGAL et al., 2002).

O tamanho médio dos fragmentos (ÁREA_MN) apresentou aumento em ambas as áreas (RDS-NG e entorno), sendo mais expressivo dentro da RDS-NG. Observou-se 
que esse índice aumentou, à medida que o número de fragmentos (NP) diminuiu, ou seja, as áreas dos fragmentos se tornaram maiores em todos os anos de estudo nesta RDS. Em 2015, a área média dos fragmentos diminuiu na área do entorno, à medida que os fragmentos (NP) aumentaram, indicando uma menor diversidade, uma vez que a riqueza das espécies depende das dimensões dos fragmentos (MCGARIGAL et al., 2002).

O parâmetro mais importante para explicar as variações de riqueza de espécies é a área do fragmento (PIVORANI et al., 2014). Os valores do índice de números de fragmentos (NP) estimados dentro da RDS-NG e seu entorno indicam que houve uma diminuição dos fragmentos pequenos em ambas as áreas, no entanto, estes ainda são predominantes no último ano de estudo (2015), correspondendo a 93\% na RDS e 88\% na área do entorno. O principal problema desse padrão é que pequenos fragmentos estão mais sujeitos ao efeito de borda (PIROVANI et al., 2014).

Os fragmentos médios e grandes também diminuíram em ambas as áreas de estudo em todo o período de análise (de 1986 a 2015). Os fragmentos grandes são importantes para a manutenção da biodiversidade e de processos ecológicos em larga escala (FORMAN; GODRON, 1986; MOREL et al., 2016). Os fragmentos pequenos também cumprem funções relevantes ao longo da paisagem, funcionando como elementos de ligação, trampolins ecológicos (stepping stones) entre grandes áreas, e atuam como refúgio para espécies que requerem ambientes particulares que só ocorrem nessas áreas.

Os fragmentos pequenos também merecem atenção especial, pois os resultados do presente estudo indicam que estarão sob grande pressão antrópica nos próximos anos na área observada. Caso não sejam adotadas medidas e estratégias adequadas de manejo das áreas de interesse, poderão ocorrer grandes impactos na interligação entre os fragmentos próximos e maiores, pois os remanescentes de vegetação nativa apresentam frágeis padrões de sustentabilidade ao longo do tempo. Muitos fragmentos são, na realidade, potenciais núcleos de colonização de florestas secundárias (PIROVANI et al., 2014). 
Os valores do índice de forma médio (SHAPE_MN) estimados neste estudo mostram que praticamente não houve uma diferenciação entre os anos estudados tanto para a RDS-NG quanto à área do entorno. Os resultados indicam que a paisagem deste estudo apresenta fragmentos florestais de formas próximas às simples, ou seja, benéficos para a conservação, com uma tendência mínima de se tornarem irregulares (MCGARIGAL et al., 2002), visto que esses valores do índice de forma média tenderam a diminuir na área deste estudo. Esse resultado tem relação com a quantidade de vegetação nativa $(45,1 \%)$ observados na RDS-NG até 2015. Para Forman (1995), quanto mais irregulares são os fragmentos, mais suscetíveis estão para apresentar maior efeito de borda, principalmente aqueles de menor área, em função da sua maior interação com a matriz (CEMIN; PERICO; REMPEL, 2009).

A dimensão fractal média (FRAC_MN) e o índice médio de circularidade dos fragmentos (CIRCLE_MN) corroboram os valores do índice de forma médio (SHAPE_ MN), já que apresentaram baixa variação e estiveram mais próximos de 1 e 0 para a RDS-NG e o seu entorno, respectivamente. Esses resultados indicam formas com perímetros muito simples, como círculos ou quadrados e menos suscetível ao efeito de borda (MCGARIGAL; MARKS, 1995).

A área central, nuclear ou core de um fragmento é o melhor indicativo da qualidade dos fragmentos do que sua área total (MCGARIGAL et al., 2002). Valores maiores indicam uma melhor qualidade da paisagem, uma vez que correspondem à área total do habitat preservado dentro dos fragmentos (CALEGARI et al., 2010).

O percentual da área central (CPLAND) apresentou uma tendência de aumento em ambas as áreas (dentro da RDS e no seu entorno), passando de 29\% para 53\% entre 1986 e 2015 dentro da RDS e de 24\% para 31\% no entorno da RDS no mesmo período. Esse resultado indica que a área de núcleo aumentou em toda a área de estudo no período de análise (MCGARIGAL; MARKS, 1995). Observou-se que esses resultados foram mais expressivos dentro da RDS-NG do que para a área de seu entorno, influenciada pela redução dos fragmentos pequenos ( $<5$ hectares) em todos 
os períodos estudados. Embora a classificação de tamanhos de fragmentos possa ser relativizada de acordo com as espécies e o ambiente, um fragmento será considerado pequeno quando não possuir integridade ecológica suficiente para manter populações viáveis de espécies com menor plasticidade ambiental (ZALLA; PIRES; SANTOS, 2004).

Tabela 9 - Métricas da paisagem estimadas para toda a área de estudo (dentro da RDS-NG e na zona de $10 \mathrm{~km}$ no entorno)

\begin{tabular}{|c|c|c|c|c|c|c|c|c|}
\hline \multirow{2}{*}{ Variável } & \multicolumn{4}{|c|}{ RDS-NG } & \multicolumn{4}{|c|}{ Entorno da RDS-NG } \\
\hline & 1986 & 1996 & 2006 & 2015 & 1986 & 1996 & 2006 & 2015 \\
\hline & \multicolumn{8}{|c|}{ Métricas de área e densidade } \\
\hline NP & 658 & 333 & 243 & 187 & 2818 & 1972 & 2224 & 2411 \\
\hline LPI & 20 & 40 & 41 & 84 & 6 & 13 & 13 & 28 \\
\hline PLAND & 54 & 72 & 77 & 84 & 49 & 59 & 58 & 60 \\
\hline \multirow[t]{2}{*}{ AREA_MN } & 31.4 & 82 & 120.9 & 176.9 & 27.2 & 46.5 & 45.4 & 38.6 \\
\hline & \multicolumn{8}{|c|}{ Métricas de forma } \\
\hline SHAPE_MN & 1.46 & 1.35 & 1.36 & 1.31 & 1.45 & 1.41 & 1.44 & 1.42 \\
\hline FRAC_MN & 1.06 & 1.05 & 1.05 & 1.05 & 1.06 & 1.057 & 1.058 & 1.06 \\
\hline \multirow[t]{2}{*}{ CIRCLE_MN } & 0.48 & 0.42 & 0.4 & 0.42 & 0.45 & 0.45 & 0.45 & 0.47 \\
\hline & \multicolumn{8}{|c|}{ Métricas de área central } \\
\hline NDCA & 382 & 286 & 247 & 205 & 1717 & 1342 & 1586 & 1769 \\
\hline CAI_MN & 2.25 & 1.53 & 1.79 & 0.62 & 1.95 & 1.67 & 1.8 & 1.59 \\
\hline \multirow[t]{2}{*}{ CPLAND } & 29 & 45 & 52 & 59 & 24 & 33 & 31 & 31 \\
\hline & \multicolumn{8}{|c|}{ Métricas de proximidade e isolamento } \\
\hline \multirow[t]{2}{*}{ PROX_MN } & 2740.4 & 11252 & 16336.2 & 39541 & 2282.3 & 7841.7 & 8058.2 & 16943.1 \\
\hline & \multicolumn{8}{|c|}{ Métricas de Conectividade } \\
\hline \multirow[t]{2}{*}{ COHESION } & 99.47 & 99.84 & 99.86 & 99.98 & 99.28 & 99.66 & 99.66 & 99.8 \\
\hline & \multicolumn{8}{|c|}{ Métricas de diversidade } \\
\hline SHDI & 0.69 & 0.6 & 0.54 & 0.44 & 0.69 & 0.68 & 0.67 & 0.68 \\
\hline SHEI & 0.99 & 0.86 & 0.78 & 0.63 & 1 & 0.98 & 0.97 & 0.98 \\
\hline
\end{tabular}

Fonte: Autores (2020)

O número de áreas do núcleo disjuntas (NDCA) diminuiu no interior da área da RDS-NG de 382 em 1986 para 205 em 2015. Esse resultado indica a redução do efeito de borda dentro da RDS-NG a partir do agrupamento de fragmentos de vegetação 
nativa mais isolados, como resultado da redução do total e densidade de bordas. Na prática, o interior da RDS-NG melhorou seu estado de conservação, uma vez que a borda é um limite permeável sujeito a impactos advindos da matriz antrópica exterior à RDS-NG, regida por legislação e normas mais flexíveis para o uso da terra e, portanto, maior probabilidade de degradação da vegetação natural (RODRIGUES; NASCIMENTO, 2006). O NDCA, entretanto, aumentou na área de entorno da RDS-NG de 1717 em 1986 para 1769 em 2015, indicando um aumento da fragmentação da vegetação natural (MCGARIGAL; MARKS, 1995).

O índice de área central média (CAI_MN) representa a percentagem média do fragmento da classe que é a área central (core área), na qual um fragmento com CAI = 0 não possui área central. No presente estudo, os valores estimados de CAI_MN para o interior da RDS-NG reduziram de 2,25\% para 0,62\% entre 1986 e 2015 . Similarmente, na área de entorno da RDS-NG, houve a redução do CAI_MN de 1,95\% para 1,59\% no mesmo período de análise. O menor valor estimado de CAI_MN indica maior efeito de borda (MCGARIGAL; MARKS, 1995).

Os resultados das estimativas do índice de proximidade (PROX-MN) indicam que os fragmentos de vegetação nativa possuíam vizinhos de mesmo tipo em todo o período desta análise, pois, tanto dentro da RDS quanto no seu entorno, não foram observados valores nulos. Os resultados revelam uma tendência de aumento da proximidade entre fragmentos, sendo que em 2015 foi observado o maior valor de PROX-MN, indicando a presença de fragmentos mais contíguos e menos isolados em toda a área de estudo.

A métrica de contágio e dispersão (COHESION) é utilizada para medir o grau de conectividade dos fragmentos de uma área de estudo. Com base nos resultados deste estudo utilizando a métrica COHESION estimaram-se aproximadamente $100 \%$ de conectividade para todos os anos analisados dentro da RDS-NG e de seu entorno. Esse resultado indica que os fragmentos da vegetação nativa mantiveram uma conectividade física e permaneceram praticamente inalterados, não havendo alterações substanciais da conectividade no período e área de estudo. Tal resultado 
indica maior agregação e, portanto, menos isolamento dos fragmentos da classe (MCGARIGAL; MARKS, 1995).

De forma geral, ao comparar a paisagem de 1986 com a de 2015 na área de estudo, observou-se que a riqueza e distribuição da abundância dos elementos que compõem a paisagem apresentaram incrementos nas condições da paisagem (índices de diversidade de Shannon - SHDI, e uniformidade de Shannon - SHEI). Esses valores mostram que a paisagem na área de estudo em 2015 está menos fragmentada e com menor uniformidade na distribuição de abundância dos elementos (MCGARIGAL; MARKS, 1995). Em ambas as áreas (dentro e no entorno da RDS-NG) predominam os fragmentos pequenos ( $<5$ hectares) que, do ponto de vista ecológico, podem suportar uma menor diversidade específica. Entretanto, essas áreas podem servir de pontos de conexão dentro da paisagem aumentando o grau de percolação das mesmas (PÉRICO; CEMIN, 2006).

\section{CONCLUSÃO}

Os diferentes usos e coberturas da terra na área de estudo apresentaram grandes variações entre 1986 e 2015, com destaque à diminuição acentuada do reflorestamento dentro da RDS-NG. Essas áreas foram, em sua maior parte, regeneradas, proporcionando o aumento das áreas de regeneração secundária dentro daquela Unidade de Conservação, que junto com as áreas de vegetação nativa, ocupavam a maioria ( 60\%) do território da RDS-NG em 2015. As áreas de reflorestamentos de eucaliptos também foram reduzidas no entorno da RDS-NG entre 1987 a 2015, sendo a maior parte substituída por pastagens ou agricultura. O processo mais intenso de antropização da vegetação natural, dentro e no entorno da RDS-NG, ocorreu no período entre 1986 e 2006.

De modo geral, observou-se que na última década houve melhoria das condições naturais, com a regeneração de remanescentes de vegetação natural, dentro da RDSNG comparado com as condições de seu entorno. Esse fato indica que havia uma 
tendência de empoderamento das comunidades locais dentro da RDS-NG para manter a integridade dessa área e que culminou com a criação de Unidade de Conservação de uso sustentável. O entorno da RDS-NG apresenta um processo mais intenso de ocupação agrícola e pecuária, mas não parece ser uma ameaça à integridade da RDSNG mediante a implementação de estratégias de desenvolvimento sustentável dessa reserva. A principal ameaça para a RDS-NG está relacionada à ocorrência dos incêndios florestais, variável anualmente, mas podem ter origem em áreas com maior presença humana, nas quais o uso do fogo para manejo da terra é permitido e adotado.

A paisagem natural da área de estudo apresentou melhores condições para a conservação da biodiversidade em 2015, quando comparada com as condições observadas em 1986. O interior da RDS Geraizeiras foi o que mais contribuiu para a melhoria dos resultados das condições de fragmentação da paisagem na área de estudo.

A elaboração e adoção de um Plano de Manejo da Reserva de Desenvolvimento Sustentável Nascentes das Geraizeiras poderia contribuir ainda mais com a definição de estratégias de proteção da RDS, a ampliação da recuperação de áreas degradadas e a conservação dos remanescentes de vegetação nativa na região. Nesse contexto, entende-se que é importante ampliar a prática de atividades econômica sustentáveis, como o aproveitamento de produtos florestais não madeireiros, os consórcios agroflorestais e outras atividades econômicas de forma moderada, que possam garantir a geração de renda e trabalho à comunidade local. Essas comunidades precisam ter garantidos os sustentos para suas famílias, com a inclusão de todos os segmentos sociais.

Por fim, considerando que predominam pequenos fragmentos de vegetação nativa na área de estudo, com destaque na área do entorno da RDS Nascentes das Geraizeiras, são necessários esforços adicionais para ampliar a união e formação de fragmentos maiores. A redução dos impactos sobre os fragmentos de vegetação nativa poderia ser feita com a implantação de usos alternativos da terra, consorciando 
elementos da vegetação local, com estímulos a adoção de mosaicos para agricultura, agroflorestal, reflorestamento e pecuária, possibilitando a existência de todos os segmentos da sociedade que compõem a reserva.

\section{AGRADECIMENTOS}

Os autores agradecem à Coordenação de Aperfeiçoamento de Pessoal de Nível Superior (CAPES) pela concessão de bolsa para a primeira autora, à Embrapa Cenargen e ao Programa de Pós-Graduação de Ciências Florestais da Universidade de Brasília (UnB).

\section{REFERÊNCIAS}

BRASIL. Conselho Nacional do Meio Ambiente. Resolução n 428, de 17 de dezembro de 2010. Diário Oficial da República Federativa do Brasil, Brasília, DF, 20 dez. 2010. Disponível em: http://www.mma.gov.br/port/conama/legiabre.cfm?codlegi=641. Acesso em: 28 ago. 2017.

CALEGARI, L. et al. Análise da dinâmica de fragmentos florestais no município de Carandaí, MG, para fins de restauração florestal. Revista Árvore, Viçosa, MG, v. 34, n. 5, p. 871-880, 2010.

CARVALHO, T. M.; CARVALHO, C. M. Sistemas de informações geográficas aplicadas à descrição de hábitats. Acta Scientiarum: Ciências Humanas e Sociais, Maringá, v. 34, p. 79-90, 2012.

CEMIN, G.; PERICO, E.; REMPEL, C. Composição e configuração da paisagem da sub-bacia do Arroio jacaré, Vale do Taquari, RS, com ênfase nas áreas de florestas. Revista Árvore, Viçosa, MG, v. 33, n. 4, p. 705-711, 2009.

CORREIA, J. R. Pedologia e conhecimento local: proposta metodológica de interlocução entre saberes construídos por pedólogos e agricultores em área de Cerrado em Rio Pardo de Minas, MG. 2005. Tese (Doutorado) - Universidade Federal Rural do Rio de Janeiro, Seropédica, 2005.

EUCLYDES, Humberto Paulo (coord.). Atlas Digital das Águas de Minas Gerais. Uma ferramenta para o planejamento e gestão dos recursos hídricos. 2. ed. Belo Horizonte: RURALMINAS; Viçosa, MG: UFV, 2007. 1 CD-ROM.

FORMAN, R. T. T.; GODRON, M. Landscape Ecology. New York: John Wiley \& Sons, 1986. 619 p.

FORMAN, R. T. T. Land mosaics: the ecology of landscapes and regions. Cambridge: Cambridge University Press, 1995. 632 p. Disponível em: https://doi.org/10.2134/ jeq1997.00472425002600030047x. Acesso em: 10 nov. 2020.

GUPTILL, S. C.; MORRISON, J. L. Elements of Spatial Data Quality. New York: Elsevier Science, 1995. 
INSTITUTO ESTADUAL DE FLORESTAS (MG). Proteção da biodiversidade em unidades de conservação. Belo Horizonte, 2014. Disponível em: http://www.ief.mg.gov.br/areasprotegidas/criacao-de-areas-protegidas. Acesso em: 20 nov.2014.

LANDIS J. R.; KOCH, G. G. The measurement of observer agreement for categorical data. Biometrics, New Jersey, v. 33, n. 1, p. 159-174, 1977.

LEITE, M. E; ALMEIDA, J. W. L.; SILVA, R. F. Análise espaço-temporal do eucalipto no Norte de Minas Gerais nos anos de 1986, 1996 e 2010. GeoTextos, Salvador, v. 8, n. 2, p. 59-74, 2012.

MAGALHÃES, F. R.; AMORIM, R. A. O movimento dos Geraizeiros e a luta pela terra no Alto do Rio Pardo. RURIS, [s. I.], v. 9, n. 2, p. 209-239, 2015.

MCGARIGAL, K.; CUSHMAN, S. A.; ENE, E. FRAGSTATS v4: Spatial Pattern Analysis Program for Categorical and Continuous Maps. Amherst: University of Massachusetts, 2012. Disponível em: http://www.umass.edu/landeco/research/fragstats/fragstats.html. Acesso em: 10 nov. 2020.

MCGARIGAL, K. et al. Fragstats v3: Spatial Pattern Analysis Program for Categorical Maps. Massachusetts: [s. n.], 2002. Disponível em: http://www.umass.edu/landeco/research/ fragstats/fragstats.html. Acesso em: 18 jan. 2015.

MCGARIGAL, K.; MARKS, B. J. Fragstats: Spatial pattern analysis program for quantifying landscape structure. Reference manual. Corvallis: Oregon State University, 1995. 59 p.

MENESES, P. R.; ALMEIDA, T. Introdução ao Processamento de Imagens de Sensoriamento Remoto. Brasília: CNPQ; UnB, 2012. 266 p.

MOREL, J. D. et al. Diferenciação da vegetação arbórea de três setores de um remanescente florestal relacionada ao seu histórico de perturbações. Ciência Florestal, Santa Maria,v. 26, n. 1, p. 81-93, 2016.

PANG, A. et al. Land use/cover change in response to driving forces of Zoige County, China. Procedia Environmental Sciences, Amsterdam, v. 2, p. 1074-1082, 2010.

PÉRICO, E.; CEMIN, G. Caracterização do município de Arvorezinha, RS, com ênfase na dinâmica dos fragmentos florestais, por meio de sistemas de informações geográficas (SIGs). Scientia Forestalis, Piracicaba, n. 70, p. 1-29, 2006.

PIROVANI, D. B. et al. Análise espacial de fragmentos florestais na Bacia do rio Itapemirim, ES. Revista Árvore, Viçosa, MG, v. 38, n. 2, p. 271-281, 2014.

QUEIROZ J. E. R. de; GOMES H. M. Introdução ao processamento digital de imagens. RITA, Porto Alegre, v. 13 n. 2 p. 11-42, 2006.

RIBEIRO M. C. et al. The Brazilian Atlantic Forest: how much is left, and how is the remaining forest distributed? Implications for conservation. Biological conservation, Amsterdam, v. 142, p. 1141-1153, 2009. 
RODRIGUES, P. J. F. P.; NASCIMENTO, M. T. Fragmentação florestal: breves considerações teóricas sobre efeitos de borda. Rodriguésia, Rio de Janeiro, v. 57, n. 1, p. 63-74, 2006. DOI: https://doi.org/10.1590/2175-7860200657105

SANTOS, A. R.; LOUZADA, F. L. R. O.; EUGENIO, F. C. ArcGIS 9.3 Total: aplicações para dados espaciais. 2. ed. Alegre: [s. n.], 2010. v. 1. 184 p. Disponível em: http://www.mundogeomatica. com.br/. Acesso em: 10 nov. 2020.

SCOLFORO,J. R.; CARVALHO, L. M. Mapeamento e Inventário da Flora e dos Reflorestamentos de Minas Gerais. Lavras: UFLA, 2006.

SOUZA, C. G. et al. Análise da fragmentação florestal da área de proteção ambiental Coqueiral, Coqueiral-MG. Ciência Florestal, Santa Maria, v. 24, n. 3, p. 631-644, 2014.

TABARELLI, M. et al. Prospects for biodiversity conservation in the Atlantic Forest: lessons from aging human-modified landscapes. Biological Conservation, Amsterdam, v. 143, n. 10, p. 2328-2340, 2010.

TABARELLI, M.; GASCON, C. Lessons from fragmentation research: improving management and policy guidelines for biodiversity conservation. Conservation Biology, New York, v. 19, n. 3, p. 734-739, 2005.

UNITED STATES. Department of the Interior. U.S. Geological survey - USGS. [S. I.], 2014. Disponível em: http://earthexplorer.usgs.gov/. Acesso em: 15 out. 2014

VELOSO, G. A.; LEITE, M. E. A Dinâmica Espaço-Temporal das Florestas Plantadas na Microrregião de Grão-Mogol. Revista Cerrados, Brasília-DF, v. 11, n. 1, p. 13-21, 2013.

VIANA, V. M.; PINHEIRO, L. A. F. V. Conservação da biodiversidade em fragmentos florestais. Série Técnica IPEF, Piracicaba, v. 12, n. 32, p. 25-42, 1998.

ZALLA, A. M.; PIRES,J. S.; SANTOS,J. E. Avaliação da integridade ecológica em Bacias Hidrográficas. In: SANTOS, J. E. et al. "Faces da Polissemia da Paisagem: Ecologia, Planejamento e Percepção". São Carlos: Editora RiMa; FAPESP, 2004.

ZARAGOZí, B. et al. Free and open source programming library for landscape metrics calculations. Environmental Modelling \& Software, [s. I.], v. 31, p. 131-140, 2012. 


\section{Contribuição de Autoria}

\section{1 - Marizete Chaves Cerqueira}

Engenheira Florestal, Ma., Pesquisadora Autônoma https://orcid.org/0000-0002-5553-0848•marizeteflorestal@gmail.com

Contribuição: Conceituação, Manipulação e Curadoria dos dados, Metodologia, Validação, Conclusões, Escrita - primeira redação, Escrita - revisão e edição

\section{2 - Eraldo Aparecido Trondoli Matricardi}

Engenheiro Florestal, PhD., Professor

https://orcid.org/0000-0002-5323-6100•ematricardi@gmail.com

Contribuição: Conceituação, Manipulação e Curadoria dos dados, Metodologia, Análise de dados, Validação, Conclusões, Escrita - revisão e edição

\section{3 - Aldicir Osni Scariot}

Engenheiro Florestal, PhD, Pesquisador https://orcid.org/0000-0003-0771-3073•aldicir.scariot@embrapa.br Contribuição: Conceituação, Administração do Projeto, Recursos, Manipulação e Curadoria dos dados, Metodologia, Análise de dados, Validação, Conclusões, Escrita primeira redação

\section{4 - Carlos Henke de Oliveira}

Biólogo, PhD, Professor

https://orcid.org/0000-0002-5242-2040•carloshenke@unb.br

Contribuição: Conceituação, Metodologia, Validação, Escrita - primeira redação

\section{Como citar este artigo}

Cerqueira, M. C.; Matricardi, E. A. T.; Scariot, A. O.; Oliveira, C. H. Fragmentação da paisagem no entorno e na Reserva de Desenvolvimento Sustentável Nascentes das Geraizeiras, Minas Gerais. Ciência Florestal, Santa Maria, v. 31, n. 2, p. 607-633, 2021. DOI 10.5902/1980509826290. Disponível em: https://doi.org/10.5902/1980509826290. Acesso em: xx mês-abreviado 2021. 